\title{
La flagrancia como procedimiento expeditivo y el resguardo de los derechos fundamentales ${ }^{1}$
}

Fernando M. Rodrigo ${ }^{2}$

\section{RESUMEN}

En el presente artículo se analiza el concepto procesal de flagrancia como situación fáctica que permite la limitación de derechos y libertades fundamentales. Concretamente, se pretende definir la flagrancia como circunstancia habilitante de la adopción de una medida cautelar sobre la libertad ambulatoria y sobre la injerencia en los derechos de la persona sometida al proceso penal. Asimismo, se analizan los principios rectores de procedimientos inmediatos o expeditos para casos de flagrancia regulados en diferentes digestos normativos en materia procesal penal, y su relación con el estado de inocencia y el actuar del Fiscal que se encuentra a cargo de la investigación penal. Se considera la utilización de la declaración del coprocesado en tanto prueba de cargo para la condena en casos penales en general y en especial en hechos flagrantes. Por último, se consideran las situaciones donde, un avance legitimado en la privacidad de las personas, provoca la verificación flagrante de un hecho ilícito ajeno al que diera progreso a la injerencia.

1 Data de recebimento: 21/06/2018. Data de aceite: 21/09/2018.

2 Abogado (Facultad de Derecho de la Universidad Nacional de Rosario -U.N.R.-, República Argentina); exPresidente de la Asociación de Fiscales del Ministerio Público de la Acusación de la Provincia de Santa Fe, República Argentina - Magister en Derecho Procesal (Facultad de Derecho de la Universidad Nacional de Rosario -U.N.R.-, República Argentina) - Mediador Penal (Ministerio de Justicia y Derechos Humanos de la Provincia de Santa Fe); Docente de la Facultad de Derecho de la Universidad Nacional de Rosario, República Argentina (cátedras de Introducción al Derecho y Derecho Penal I-Parte General-); exProfesor del Instituto de Seguridad Pública (I.Se.P.) -ex Escuela de Cadetes de Policías- de la Provincia de Santa Fe, República Argentina. Miembro de la Asociación Internacional de Derecho Penal (AIDP) y de International Association of Prosecutors (IAP). E-mail: fernandorodrigo1@gmail.com 
Palabras clave: Flagrancia delictiva. Derechos fundamentales. Presunción de flagrancia. Proceso Penal.

\section{LA FLAGRANCIA Y EL SISTEMA PROCESAL}

El sistema procesal es uno de los instrumentos decisivos para la libertad política, pues resulta el ámbito fundamental a través del cual se desenvuelve y dinamiza la potestad del Estado. Por eso, cada instituto, concepto o tipo escogido dentro de los códigos procesales, determina el aseguramiento de las dos referencias que hacen a la vida en sociedad: la libertad y el orden.

Estos aspectos se ven reflejados necesariamente en el análisis de la flagrancia, puesto que la misma caracteriza un comportamiento por su evidencia, permite avanzar, limitando la libertad de movimiento e incluso la intimidad del sujeto observado, para neutralizar un delito en progreso o sus consecuencias; al mismo tiempo esa evidencia haría, aparentemente, indiscutible el juicio -certeza- sobre la naturaleza ilícita de lo observado.

La flagrancia desenvuelve su competencia normativa a través de dos instancias diferentes: legitimando las restricciones a derechos fundamentales ${ }^{3} \mathrm{y}$ aportando eficacia demostrativa (probatoria) sobre el hecho y la imputación personal.

Por un lado, en el primer nivel de incidencia, se verifica particularmente justificando ciertas injerencias en la libertad ambulatoria y en la privacidad de las personas que han sido percibidas en la flagrancia delictiva.

Por el otro, en una instancia secundaria y merced a la aptitud que se le reconoce a la flagrancia dentro de la consideración misma del objeto del proceso penal, se le concede importancia para alcanzar la verdad sobre los hechos. Verdad que incluye la comprensión normativa de lo acontecido de cara a la estructura dogmática que

3 YACOBUCCI, 2017, p. 37. 
configura el injusto culpable. Una consecuencia de esa apreciación es el vínculo de la flagrancia -en muchos casos- con formas especiales de procedimiento marcadas por la inmediatez con el suceso y la brevedad de los plazos para la resolución sobre el fondo del conflicto.

Limitación de derechos y celeridad resolutiva como corolarios de la flagrancia, se explican en virtud de la idea generalizada de que lo empírico, evidentemente, resulta de sencilla apreciación, aún en el ámbito normativo, que es aquel donde se desenvuelve la imputación penal.

Como explica Taruffo, no se está propiamente hablando de un fundamento para distinguir de manera tajante entre una verdad procesal y una verdad real. Sucede que el proceso puede limitar, reglar o condicionar la búsqueda de la verdad, pero eso no significa que se persiga una verdad diversa dentro del proceso de aquella que se podría descubrir fuera de este. La verdad procesal es limitada o incompleta en razón del cauce formal al que se halla atada ${ }^{4}$, es que la verdad absoluta no existe ${ }^{5}$, es más bien un problema filosófico, tal verdad es imposible de alcanzar en un proceso, de hecho, la idea de una verdad absoluta puede ser una hipótesis abstracta en un contexto filosófico amplio,

pero no se puede sostener racionalmente que una verdad absoluta pueda o deba ser establecida en ningún dominio del conocimiento humano, y ni qué decir tiende del contexto judicial. Ni siquiera las ciencias duras, como la física y las matemáticas, pretenden ser ya capaces de alcanzar verdades absolutas; de hecho, la idea de una verdad absoluta parece pertenecer sólo a los terrenos de la religión y la metafísica. En realidad, en todo contexto científico y empírico, incluido el de los procesos judiciales, la verdad es relativa 6 .

4 TARUFFO, 2010, ps. 101 y ss.

5 Debe agregarse a las dificultades señaladas, las que provienen o son impuestas por las propias normas jurídicas "que obligan siempre (por lo menos en un estado de Derecho) a tener en cuenta y a respetar en esta tarea determinados principios y derechos fundamentales del acusado, que impiden la valoración de pruebas obtenidas ilícitamente o con violación a los derechos fundamentales", en MUÑOZ CONDE, 2007, p. 14.

6 TARUFFO, 2002, p. 26. 


\section{APROXIMACIÓN A LA DEFINICIÓN NOMINAL DE FLAGRANCIA}

La palabra "flagrante" tiene origen latino en los términos flagrans o flagrantis, en su función adjetiva señala la actualidad de la ejecución, en tanto en su forma adverbial es indicativa de que el observador tiene ante sí el desarrollo de algo, en materia penal, de un delito ${ }^{7}$. En su formación latina de naturaleza verbal se refiere pues a lo que está en llamas y ardiendo; en otras palabras, lo flagrante es tanto lo que despide luz: "Que flagra"; como lo "que se está ejecutando actualmente". También "de tal evidencia que no necesita pruebas. Contradicción flagrante". Y la locución en flagrante: "En el mismo momento de estarse cometiendo un delito, sin que el autor haya podido huir".

Los anglosajones utilizan la idea de estar en o al rojo, en caliente o de red hands, para expresar una situación análoga, en tal sentido y como regla general en lo referente a las excepciones que legitiman detenciones y requisas sin orden judicial, la Suprema Corte de los Estados Unidos de Norteamérica (SC U.S.) ha dado especial relevancia al momento y lugar en que tuvo lugar el procedimiento y a la existencia de razones urgentes para corroborarlo, habiendo convalidado arrestos sin mandamiento judicial practicados a la luz del día y en lugares públicos (“United States v. Watson" 423, U.S., 411 -1976-), como también los verificados al interceptar un vehículo.

Es así que el delito descubierto en flagrancia está claro (o parece estarlo). La presencia de la autoridad o del público en el momento mismo de la ejecución echan luz sobre los hechos ${ }^{8}$, de acuerdo al brocardo, in claris cessat interpretatio, en el proceso penal, in claris cessat investigatio.

7 En alemán, el hecho flagrante es literalmente el "hecho exhibido públicamente" (offenkundige Tatsache).

8 Bien que "el delito solo se considera in fraganti respecto del que haya presenciado su perpetración", en RUBIANES, 1978, Tomo III, p. 107. 
Manzini expone que

la noticia de un hecho constitutivo de delito se puede tener del modo más inmediato y convincente mediante la asistencia a la perpetración de ese mismo hecho, o por efecto de consecuencias o reacciones inmediatamente producidas por él (...) El concepto jurídico de flagrancia está constituido por una idea de relación entre el hecho y el delincuente" ${ }^{\prime \prime}$.

En el mismo sentido, Cabanellas:

En flagrante. Esta locución adverbial requiere la concurrencia de dos circunstancias, una de ellas de índole penal y de carácter procesal la otra. Lo primero se refiere a la etapa de comisión u omisión punible, por la que atraviesa necesariamente todo delito consumado o en grado notorio de ejecución; lo segundo se relaciona con la observación de la actividad delictiva por uno o más testigos y con la detención del responsable antes de haber concluido la manifestación delictiva y haberse puesto a salvo, lejos del lugar de los hechos o luego de haber podido adoptar, aun permaneciendo en ellos, actitud de inocencia, cuando menos aparente ${ }^{10}$.

En el Antiguo Testamento, la infracción descubierta en flagrancia merecía pena mayor que la presumida tras las rudimentarias y dudosas investigaciones de época. En Levítico 20, 10 se estatuye que la mujer sorprendida en adulterio flagrante debía ser lapidada, norma que fue abrogada con la venida misericordiosa de Cristo: Juan 8, 4. En tanto que el profeta Jeremías habla de cómo queda avergonzado un ladrón cuando es descubierto (Jeremías 2, 26).

En la actualidad, la función principal del instituto es excepcionar el principio de que nadie puede ser arrestado sino en virtud de orden escrita de autoridad competente, diferentes constituciones nacionales receptan ello, verbigracia, art. 18 de la Constitución de la República Argentina, art. 12 de la Constitución de la República del Paraguay o el

9 MANZINI, 1953, Tomo IV, p. 128.

10 CABANELLAS, 1981, Tomo IV, p. 83. El mismo autor y en el mismo lugar desarrolló una sutil disquisición entre flagrante delito y delito flagrante; como entre legítima defensa y defensa legítima. 
art. $5^{\circ}$ inc. LX de la Constitución de la República Federativa de Brasil.

Tras establecer lo antedicho, los códigos se dedican a definir (actividad peligrosa) la flagrancia, con los acostumbrados matices y variaciones del folklore procesal penal. En tanto que la sesuda doctrina clasifica distintas formas de flagrancia: la flagrancia a secas o propia, la flagrancia impropia o cuasiflagrancia y la flagrancia presunta o ficta.

Y por cierto que el delito permanente es flagrante hasta tanto haya cesado la permanencia, por ejemplo, un secuestro de persona (delito permanente) puede llevar ya meses o años, pero no cesa por ello de ser flagrante si se sorprende al delincuente en el acto de proseguir la custodia de su víctima ${ }^{11}$. De acuerdo a la Corte Federal alemana (Bundesgerichtshof), en sentencia del 10-04-2002 - NJW 2002, 2115 , el holocausto del gobierno nacionalsocialista fue infligido "en flagrancia", en cuyo caso toda actividad probatoria sobre la existencia del hecho resulta dispendiosa, para Krehl, "la flagrancia convierte el hecho en público y notorio, incluso para el tribunal"12.

\section{FUNCIONALIDAD DEL TIPO DE FLAGRANCIA}

\subsection{Proporcionalidad y razonabilidad en las injerencias en derechos fundamentales}

La idoneidad, necesidad, eficacia y relación de adecuación con el fin no pueden progresar entonces, si la autorización de la injerencia no se encuentra antes establecida por una ley ${ }^{13}$. La flagrancia es un supuesto normativo que, al formularse mediante la legislación pro-

\footnotetext{
11 SOLER, 1992, Tomo II, ps. 191/3.

12 KREHL, 2013, p. 544.

13 "El principio de proporcionalidad en sentido estricto significa que la aplicación de un determinado instrumento o medio para alcanzar un determinado objeto o finalidad no debe ser irrazonable en sus relaciones recíprocas", en GAVARA DE CARA, Juan Carlos, Derechos fundamentales y desarrollo legislativo. La garantía del contenido esencial de los derechos fundamentales en la Ley Fundamental de Bonn, Centro de Estudios Constitucionales, Madrid, 1994, p. 308; con cita de BVerfGE 7, 377; 8, 71; 13,$97 ; 78,77 ; \mathrm{y} 79,29$.
} 
cesal penal, actúa como circunstancia legitimadora de la operatoria de los funcionarios y debe ser puesta en relación con el principio de proporcionalidad, además de su evaluación en términos de tipicidad conceptual. Los modelos procedimentales en la materia son modos de concreción de las exigencias constitucionales para justificar el avance sobre la intimidad o privacidad de las personas ${ }^{14}$.

La razonabilidad y proporcionalidad vinculan medios y fines no de manera meramente instrumental sino implicándolos en su valoración material ${ }^{15}$. En el derecho penal, tanto sustantivo como procesal, la razonabilidad se ejerce en gran medida a través de la proporcionalidad cuando se habla de limitaciones de derechos y libertades en aras de objetivos de seguridad y punibilidad. La Corte Interamericana de Derechos Humanos ha explicado que "a fin de que el Estado pueda satisfacer legítimamente un interés social y encontrar un justo equilibrio con el interés del particular, debe utilizar los medios proporcionales a fin de vulnerar en la menor medida el derecho a la propiedad de la persona objeto de la restricción"16.

Este paradigma opera en dos direcciones, la primera como sistema de límites a la libertad salvaje de los asociados, mediante la prohibición, la investigación y el castigo como delitos de las ofensas a los derechos ajenos o a otros bienes o intereses estipulados como fundamentales, y la otra dirección está dada como sistema de límites a la potestad punitiva del Estado, mediante las garantías penales y procesales, que impiden la prohibición de las acciones inofensivas o no culpables y el castigo de las ofensivas y culpables sin una previa y correcta averiguación.

14 YACOBUCCI, 2017, p. 37.

15 SANGUINÉ, 2014, cap. Sexto.

16 Corte IDH, caso "Salvador Chiriboga vs. Ecuador", sentencia de 06 de mayo de 2008, párr. 63. Asimismo, sostuvo que "la restricción de los derechos consagrados en la Convención debe ser proporcional al interés de la justicia y ajustarse estrechamente al logro de ese objetivo, interfiriendo en la menor medida posible en el efectivo ejercicio de (un) derecho (...)", cfr. caso "Herrera Ulloa Vs. Costa Rica", sentencia de 2 de julio de 2004, párr. 123. 
Estas dos direcciones del garantismo penal corresponden a dos fines, que a juicio de Ferrajoli justifican el poder punitivo

\begin{abstract}
"la prevención de los delitos, es decir, de los ataques injustos; la prevención de las penas informales o excesivas, es decir, de los castigos injustos. Las finalidades preventivas del primer tipo, o sea, la tutela de los ciudadanos frente a los posibles delincuentes, se procuran mediante las garantías, primarias y secundarias, que consisten, en los límites impuestos a las meras libertades salvajes de los asociados por las normas penales, primarias y secundarias, que establecen, respectivamente, los delitos y las penas. Las finalidades preventivas del segundo tipo, es decir, la tutela de los posibles culpables de delito frente a los abusos punitivos, se persiguen a través de las garantías penales y procesales, primarias aquéllas y secundarias éstas, consistentes en límites impuestos a la potestad punitiva por los derechos de libertad y por las normas procesales. De ahí la relevancia constitucional del derecho penal"17.
\end{abstract}

Sobre esos razonamientos, Sanguiné critica la orientación punitiva que fundamente la aprehensión en flagrancia y descarta que pueda dirigirse a objetivos de ejemplaridad -exigencia de exemplaridade- o para satisfacer la opinión pública a través de una intervención eficaz y pronta del órgano estatal ${ }^{18}$.

Cuando se habla de proporcionalidad, se hace referencia a los elementos propios de un sistema jurídico que se atiene a las exigencias del Estado de derecho; en este caso, se expresan a través de los criterios de idoneidad (Geeignetheit), necesidad (Erforderlichkeit) y la exigibilidad y proporcionalidad en sentido estricto (Zumutbarkeit) en el trato justo y de gravamen adecuado para el ciudadano ${ }^{19}$, es que el principio de proporcionalidad tiene una función institucional que opera como presupuesto de constitucionalidad de las medidas que restringen principios y derechos constitucionales, en este sentido el

17 FERRAJOLI, 2011, Volumen II, p. 347.

18 SANGUINÉ, 2014, ps. 166 y ss.

19 HASSEMER, Wilfried, El principio de proporcionalidad como límite de las intervenciones jurídico-penales, en AA.VV., Límites al derecho penal, Atelier, Barcelona, 2014, ps. 193 y ss. 
Tribunal Constitucional de España (TCE) ha expresado que

(e)l ámbito en el que normalmente y de forma muy particular resulta aplicable el principio de proporcionalidad es el de los derechos fundamentales. Así ha venido reconociéndolo este Tribunal en numerosas Sentencias en las que se ha declarado que la desproporción entre el fin perseguido y los medios empleados para conseguirlo puede dar lugar a un enjuiciamiento desde la perspectiva constitucional cuando esa falta de proporción implica un sacrificio excesivo e innecesario de los derechos que la Constitución garantiza $(\ldots)^{\prime \prime 20}$.

\subsection{Un proceso breve: celeridad procesal y garantías}

La legitimación de las injerencias y de la proporcionalidad que surge de las situaciones de flagrancia se relaciona con una segunda consideración de naturaleza funcional, con sistemas especiales de procedimiento para los casos de flagrancia, que ofrecen la oportunidad de un juzgamiento abreviado, como por ejemplo lo establece la Ley $\mathrm{N}^{\circ} 27.272^{21}$ que disciplina un esquema dentro del Código Procesal Penal de la Nación (Argentina), el de la Ley $\mathrm{N}^{\circ} 13.811^{22}$ que lo incorpora al Código Procesal Penal de la Provincia de Buenos Aires (Argentina), la Ley $\mathrm{N}^{\circ} 13.472^{23}$ que lo introduce en el Código Procesal Penal de la Provincia de Santa Fe (Argentina), en el derecho com-

20 STCE 55/1996, 28 de marzo de 1996; en el mismo sentido, y con anterioridad, puede v. en SSTC $62 / 1982$, fundamento jurídico $5^{\circ} ; 66 / 1985$, fundamento jurídico, $1^{\circ} ; 19 / 1988$, fundamento jurídico $8^{\circ} ; 85 / 1992$, fundamento jurídico $5^{\circ} ; 50 / 1995$, fundamento jurídico $7^{\circ}$ ). Incluso ha hecho referencia al principio de proporcionalidad como principio derivado del valor justicia en: SSTC 160/1987, fundamento jurídico $6^{\circ} ; 50 / 1995$, fundamento jurídico $7^{\circ} ; 173 / 1995$, fundamento jurídico $2^{\circ}$ ), del principio del Estado de Derecho (STC 160/1987, fundamento jurídico $6^{\circ}$ ), del principio de interdicción de la arbitrariedad de los poderes públicos (STC 6/1988, fundamento jurídico $3^{\circ} ; 50 / 1995$, fundamento jurídico $7^{\circ}$ ) o de la dignidad de la persona (STC 160/1987, fundamento jurídico $6^{\circ}$ ), se ha aludido a este principio en el contexto de la incidencia de la actuación de los poderes públicos en el ámbito de concretos y determinados derechos constitucionales de los ciudadanos.

21 Puede c. en http://servicios.infoleg.gob.ar/infolegInternet/anexos/265000-269999/268408/norma. htm; se ha declarado la constitucionalidad del procedimiento especial a nivel nacional, verbigracia, por Cámara Nacional Criminal y Correccional (CN Crim. Y Correc.), sala VII, 15/12/2016, in re "A., L. S/ Hurto. Inconstitucionalidad. Nulidad. Excarcelación".

22 Puede c. en http://www.gob.gba.gov.ar/legislacion/legislacion/l-13811.html

23 Puede v. en https://www.santafe.gov.ar/normativa/getFile.php?id=248747\&item $=127354 \&$ cod=0 ff95bb13e3c457445e3f03330d575el 
parado se encuentra regulado, verbigracia, en el Código Orgánico Procesal Penal de la República Bolivariana de Venezuela (arts. 372 y siguientes), el Código Procesal Penal de la República del Perú (arts. 446 y ss., conforme Decreto Legislativo $N^{\circ} 1194$ ), por otra parte un modelo diferente a los citados, sobre el que puede reflexionarse, se encuentra en el Codice di Procedura Penale della Repubblica Italiana.

La consideración jurisdiccional de esos casos, aún dentro de un proceso simplificado, debe atender a dos factores que por principio resultan indisponibles. El primero es analizar la prueba de cargo presentada por el acusador, ya que esta, incluso en casos de flagrancia, debe atenerse al marco de legalidad y constitucionalidad que disciplina toda imputación penal. Desde una segunda perspectiva, la atención debe ser dirigida a la eficacia demostrativa de esos elementos de juicio, pues la evidencia debe ser sostenida dentro de una instancia de contradicción, o si se quiere debate, donde pueden concurrir pruebas que pongan en crisis inicial suficiencia de lo observado o recogido en la escena del hecho.

La cuestión aparece vinculada con el respeto por las garantías y la búsqueda de la eficacia. En general estos aspectos se presentan en una relación dialéctica, como si fueran confronte donde se tiene que optar por uno de los términos ${ }^{24}$. La realidad es que no puede haber un sistema procesal eficaz sin garantías que aseguren la legalidad y legitimidad de las consecuencias jurídicas pues, finalmente, los resultados que se obtengan serán constitucionalmente inoponibles a las personas; al mismo tiempo, un sistema ineficaz, a la postre, termina afectando radicalmente las garantías.

El asunto se muestra particularmente complejo ante la comprensión del proceso como percepción meramente empírica; sin embargo, todo sistema abreviado o rápido fundado en los elementos de investigación o en elementos de prueba ${ }^{25}$ debe ser sometido a un test de

24 YACOBUCCI, 2017, p. 62.

25 Todo lo que se logre conocer y obtener durante la etapa de investigación no tiene valor probatorio y por ello la denominación de elementos de investigación; para diferenciarlos de los elementos de 
constitucionalidad, pues sean cuales fueran las circunstancias que justifican su particularidad, lo cierto es que mantiene la consideración del proceso como un mal, se trata de un padecimiento que afecta a las personas, limitándolas en sus derechos fundamentales, aunque todavía no se haya impuesto una sanción penal, ello alcanza una importancia peculiar frente a la aplicación de medidas cautelares, en donde se encuentra de manera intensiva la privación de la libertad ambulatoria, a través del arresto, la detención ${ }^{26}$ o de la prisión preventiva ${ }^{27}$, cuyo objetivo sólo puede ser el aseguramiento de los fines del proceso cuando no haya una medida menos lesiva ${ }^{28}$.

Lo excepcional de dichos procedimientos se funda en la sencillez que supone la recolección de prueba de un hecho flagrante. Por eso, cuando acontezca situaciones que materialmente remitan a la flagrancia, si presuponen cierto nivel de complejidad probatoria, pueden quedar fuera de este sistema, por ejemplo, si es necesario recurrir a pericias, informes técnicos, dictámenes de especialistas, tramitaciones en jurisdicción ajena.

prueba, que son los que se realizan produciéndolos durante la etapa intermedia y/o durante el juicio oral mediante el ofrecimiento por las partes de aquellos elementos de investigación, que han conocido, incautado, entrevistado y demás durante esa etapa.

26 En las legislaciones que se enmarcan en un sistema acusatorio se diferencia el arresto de la detención, entendiendo que el arresto es una medida que se da en el primer momento de la Investigación Penal Preparatoria no fuere posible individualizar a los presuntos responsables y a los testigos, se podrá disponer que los presentes no se alejen del lugar, ni se comuniquen entre sí antes de declarar, en cambio, la detención procede por orden del Fiscal y cuando fuere procedente la prisión preventiva, ejemplo de ello puede v. en los arts. 211 y 214 del Código Procesal Penal de la Provincia de Santa Fe, República Argentina.

27 Sobre la prisión preventiva puede c. RODRIGO, Fernando M., Hacia una aplicación más imparcial de la prisión preventiva, en, AA.VV., Revista Jurídica de Derecho Procesal, del Instituto Panamericano de Derecho Procesal - Capítulo Paraguay, primera edición, Director Joel Melgarejo Allegretto, Editorial Marben Editora \& Gráfica S.A., 2013.

28 La Corte IDH sostuvo que “(...) la prisión preventiva es una medida cautelar, no punitiva. Este concepto está expresado en múltiples instrumentos del derecho internacional de los derechos humanos y, entre otros, en el Pacto Internacional de Derechos Civiles y Políticos, que dispone que la prisión preventiva de las personas que hayan de ser juzgadas no debe ser la regla general (art. 9.3). En caso contrario se estaría cometiendo una injusticia al privar de libertad, por un plazo desproporcionado respecto de la pena que correspondería al delito imputado, a personas cuya responsabilidad criminal no ha sido establecida. Sería lo mismo que anticipar una pena a la sentencia, lo cual está en contra de principios generales del derecho universalmente reconocidos", caso "Suárez Rosero Vs. Ecuador", sentencia de 12 de noviembre de 1997, párr. 77; más recientemente esto ha sido recordado por la Comisión IDH, Informe 35/07, emitido en el caso "Peirano Basso vs. Uruguay", 01 de mayo de 2007, ratificado en todos sus términos en el Informe 86/09, de 06 de agosto de 2009. 


\subsection{Estado de Inocencia, flagrancia y actuación del Fiscal}

En virtud que los sistemas de juicio especial, donde lo sumario de la investigación y la brevedad de los plazos no neutralizan el marco de garantías que exige el debido proceso, resulta importante analizar la flagrancia y su imputación penal con la notoriedad que brindan los elementos de investigación o elementos de prueba.

El estado de inocencia ${ }^{29}$ rige el tratamiento que debe darse a cualquier persona que se vea inmersa como sujeto pasivo de un proceso penal, así se impone tratar al imputado como si fuera inocente hasta que recaiga sentencia que declare su culpabilidad; en otras palabras, la garantía procesal que otorga aquí la presunción de inocencia supone que el Estado no puede tratar al ciudadano de otra forma que como inocente hasta que un juez, después de un debido proceso, no declare probada su culpabilidad.

Dentro de este contexto, es importante remarcar la doble valencia del estado de inocencia, que opera, por un lado, en la instancia de injerencia del funcionario público a través de la restricción de la libertad ambulatoria, la intimidad y la privacidad; y, por el otro, en la instancia de investigación, enjuiciamiento y resolución del caso.

En el primer supuesto, la flagrancia habilita una restricción de la libertad inicial que luego quedará sometida a la evaluación general de los riesgos procesales para discernir la aplicación de la prisión preventiva.

En el segundo caso, el principio de inocencia se relaciona con la carga de la prueba en cabeza del acusador, cierto que, en muchos sucesos, la flagrancia hace que al mismo tiempo de verificarse la intervención del funcionario público, el material que se recolecta o

29 La presunción de inocencia, más que un principio, es un estado, tal tesitura es sostenida por Clariá Olmedo al expresar que "en la Declaración de los Derechos del Hombre y del Ciudadano, el principio fue formulado como 'presunción' (IX) pero no cabe duda de que es más correcto expresarlo como 'estado' ya sea en su formulación positiva como en la negativa: de inocencia o de no culpabilidad. Es un estado que se conserva (se mantiene invariable) hasta que una sentencia firme, conclusiva de un proceso regular y legal, declare la culpabilidad del imputado", cfr. CLARIÁ OLMEDO, 1998, tomo I, p. 68. 
levantan en el marco de su actuación tenga una clara orientación incriminatoria, de lo que deriva, que sin alterar el onus probandi, ni invertir el principio sobre la carga de la prueba, será tarea de la defensa demostrar que lo evidente no permite motivar la imputación.

En consecuencia, en los sistemas simplificados y orales se exige capacidad de litigar de los fiscales, la identificación de estrategias e interrogatorios, esto es, la necesidad de idoneidad profesional para demostrar y argumentar sobre la imputación, en otras palabras, el órgano acusador debe analizar dentro del continuo empírico aquello que efectivamente posee relevancia en términos de imputación de un injusto típico y, en este caso, de su calidad de flagrante, debe saber a dónde se dirige a partir de los elementos colectados y que deben mostrar un significado normativo que permita aislarlos y presentarlos penalmente.

\section{LA DECLARACIÓN DEL COIMPUTADO EN CASOS DE FLAGRANCIA}

Se debate sobre la utilización de la declaración de imputación del coprocesado en tanto prueba de cargo para la condena en casos penales en general y en especial en hechos flagrantes.

Al carecer de normas específicas que regulen la cuestión o veden la utilización de las manifestaciones del coimputado, los magistrados han de valerse de reglas generales que respeten aquellos estándares definidos anteriormente, debiéndose someter que es un medio de prueba que debe someterse a una crítica intensa.

En el derecho comparado, la legislación procesal italiana ha establecido históricamente criterios de ponderación de la capacidad probatoria de las manifestaciones de cargo de los coimputados, de tal modo el artículo $192.3^{30}$ del Codice di Procedura Penale della

30 Art. 192. "Valutazione della prova (...) 3. Le dichiarazioni rese dal coimputato del medesimo reato o da persona imputata in un procedimento connesso a norma dell'articolo 12 sono valutate unitamente agli altri elementi di prova che ne confermano l'attendibilita". 
Repubblica Italiana, establece que las declaraciones del coimputado procesado en el mismo delito u otro conexo, deben ser evaluadas en el contexto de los demás elementos de juicio que las confirmen, sin que por sí mismas resulten inválidas como prueba.

Por su parte, la jurisprudencia española ha considerado este criterio al señalar que, si bien no ha de desecharse la versión incriminatoria del coimputado, no puede operar como fundamento exclusivo de la condena, ni ser única prueba de cargo $^{31}$, en virtud de que el acusado, a diferencia del testigo, no sólo no tiene obligación de decir la verdad, sino que puede callar total o parcialmente en virtud de los derechos a no declarar contra sí mismo y a no confesarse culpable ${ }^{32}$.

La declaración incriminatoria del coimputado tendrá consistencia cuando resulte corroborada por otras pruebas en contra de a quien se dirige ${ }^{33}$; debiéndose, además, considerar la personalidad del delincuente delator y las relaciones que precedentemente mantuviese con designado por él como coparticipe, examinándose la posible existencia de móviles turbios e inconfesables -por ejemplo, venganza, odio personal, resentimiento, soborno, etcétera- que impulsando a la acusación permitan tildar el testimonio de falso o espurio, o, al menos, restarle fuerte dosis de verosimilitud o credibilidad; pudiendo utilizarse en el caso de las audiencias orales del juicio las declaraciones previas de la investigación realizadas por el coimputado a los fines de demostrar las inconsistencias o las circunstancias anteriormente mencionadas.

Todas estas reglas responden a criterios de razonabilidad, experiencia común y sana crítica válidamente aplicables a todo proceso penal ${ }^{34}$.

31 SSTCE 49/98, de 02 de marzo de 1998 y 115/98, de 01 de junio de 1998, entre otras.

32 El artículo 14.3.g) del Pacto Internacional de Derechos Civiles y Políticos (ONU), establece que el inculpado no puede ser obligado a declarar contra sí mismo ni a confesarse culpable.

33 STSE 6749, 24 de septiembre de 1996. También puede consultarse JAÉN VALLEJO, Manuel, Tendencias actuales de la jurisprudencia constitucional penal: Las garantías del proceso penal, Dykinson, Madrid, 2002, ps. 140 y ss.

34 YACOBUCCI, 2017, p. 81. 


\section{FLAGRANCIA Y PRIVACIDAD: PLAIN VIEW Y HALLAZGOS CASUALES}

Las situaciones donde, un avance legitimado en la privacidad de las personas, provoca la verificación flagrante de un hecho ilícito ajeno al que diera progreso a la injerencia, lo que ha de ponderarse es la aceptación como prueba de aquella evidencia que es ajena al fin de la injerencia pero que surge de una observación o verificación inmediata -flagrante- de los funcionarios, tal los casos donde se autoriza judicialmente el allanamiento buscando determinados objetos relacionados con un delito específico investigado y, en su búsqueda, se percibe una situación de flagrante delito.

En los supuestos como los indicados la jurisprudencia norteamericana conformó el tipo de plain view que, en algunos casos, ha sido adoptado por la jurisprudencia comparada y, en otros, ha sido replicado bajo la denominación de hallazgos casuales.

Bajo la denominación de plain view la jurisprudencia de la Suprema Corte de Estados Unidos (SC U.S.), ha integrado los casos en que la adquisición de evidencia se considera dentro de los límites y garantías de la Cuarta Enmienda ${ }^{35}$ a pesar de surgir de un objetivo que trasciende la finalidad de la injerencia.

En el precedente "Horton v. California"36 se indicó que, para sostener esencialmente que no se ha violado esa garantía, en casos donde se procede sin orden de allanamiento relacionada con la recolección de evidencia que ha sido alcanzada en una situación de plainly viewed, es requisito que haya una legitimación para el ingreso al domicilio; en ese orden, se precisó que la cuestión no pasaba por aspectos subjetivos del obrar de los funcionarios -la esperanza de encontrar algo más que lo inicialmente buscado- sino por indicadores de tipo objetivo.

35 La cuarta enmienda de la Constitución de los Estados Unidos protege dos derechos fundamentales: el derecho a la privacidad y el derecho a no sufrir una invasión arbitraria.

36 496, U.S., 128 (1990), puede c. en https://supreme.justia.com/cases/federal/us/496/128/ (consultada $28 / 07 / 2018)$. 
En términos que no dejan lugar a dudas y se dirigen a decisiones de las cortes locales, la SC U.S. en el precedente "Brigham City v. Stuart" ${ }^{\prime 37}$, remarca que repetidamente ha descartado el enfoque subjetivo (subjective approach), sosteniendo que las circunstancias sustentada en aspectos objetivos habilitan el actuar ${ }^{38}$, en el caso de que los funcionarios fabriquen la excusa para la injerencia causa la falta de base de legitimación, afectándose las diligencias de hallazgo en plain view, conforme la noción del fruto del árbol envenenado.

En la jurisprudencia española se ha configurado la noción de hallazgos casuales para dar respuesta a aquellas situaciones donde, progresando una injerencia motivada en objetivos específicos que la han autorizado, se hallan de modo flagrante pruebas o elementos de investigación de un delito diverso, el marco en que se formula este estándar integra no solo los allanamientos de domicilio o registros vehiculares, sino también, supuestos donde la injerencia recae en comunicaciones o contacto telefónico; sosteniéndose que "si en la práctica del registro aparecen objetos constitutivos de un cuerpo de posible delito distinto a aquél para cuya investigación se extendió el mandamiento habilitante, tal descubrimiento se instala en la nota de flagrancia"39, por lo que, producida tal situación, la inmediata recogida de las mismas no es sino consecuencia de la norma contenida en el proceso penal español.

Esta tesis se repite en otras sentencias del Tribunal Superior de España (TSE), recogidas en la STS de 5 de julio de 2004, donde se expresó que

el dictado del auto habilitante lo fuera por delito distinto, no comporta necesariamente la nulidad de la prueba", reafir-

37547 U.S. 398, 404-05 (2006), puede c. en Harvard Law Review, Volume 124, Number 4, February 2016. 38 "An action is 'reasonable' under the Fourth Amendment, regardless of the individual officer's state of mind, 'as long as the circumstances, viewed objectively, justify the action', the officer's subjective motivation is irrelevant. It there-fore does not matter here-even if their subjective motives could be so neatly (...)", KANOVITZ, Jacqueline R., Constitucional Law, thirteenth edition, Rutledge, New York, 2012, p. 601.

39 STSE 981/2003, 03 de julio de 2003; también STSE 167/2010. 
mando la teoría de que "si el hallazgo es casual, no por ello deja de tener valor lo encontrado, siempre que estemos en presencia de flagrancia delictiva y, además, que los objetos hallados (...) se hayan introducido en el plenario mediante la declaración testifical de los intervinientes en el registro practicado con todas las garantías ${ }^{40}$.

Para el TSE, la flagrancia delictiva es suficientemente ilustrativa, palpable y evidente, que da sobrada cobertura al auto judicial del registro, con el que fue practicada la diligencia, donde el presupuesto común de todos los casos es el hallazgo de elementos de investigación o probatorios de un determinado delito cuando se produce en el curso de la investigación autorizada por otro delito distinto.

\section{CONCLUSIÓN}

Las cuestiones expresadas son las que exigen, desde el punto de vista de las garantías constitucionales, determinar las finalidades y funciones de este tipo procesal pues, a partir de allí, se deberán tomar en consideración aspectos que hacen al test de constitucionalidad, tanto de los enunciados procesales, como de su contenido material y operatividad en los casos concretos.

La flagrancia es una de las modalidades de la evidencia, una de las vías que conducen a la certeza de un dato cualquiera. Sólo habrá flagrancia si el conocimiento fundado que conduce a la certidumbre es resultado de la percepción sensorial directa e inmediata del hecho delictivo que se está cometiendo o se acaba de cometer, no siendo por tanto bastantes las presunciones, sospechas o conjeturas, por mucho que indiquen la probable comisión de un delito; debiendo, la conducta de los funcionarios encargados de la investigación, acusación y juzgamiento de casos flagrantes, respetar los derechos fundamentales.

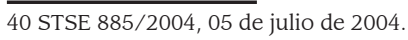


Los fines y funciones de la noción de flagrancia serán las que le otorguen el significado normativo último al concepto y al enunciado del tipo procesal, configurarán su modo de aplicación y, a partir de estas, las reglas de ponderación a las que deberá someterse cada situación que se presente a las instancias de actuación policial, ejercicio de la acción penal por parte de los Fiscal del Ministerio Público, y los Jueces que deberán ejercer el control general durante la investigación y en su caso del juicio oral.

\section{FLAGRANCY AS AN EXPEDITED PROCEDURE AND THE PROTECTION OF FUNDAMENTAL RIGHTS}

\section{ABSTRACT}

This article analyzes the concept of criminal red-handed, their characteristics and existing classes in the current procedural doctrine. Make a count of fundamental rights that may be affected in case the assumption of criminal flagrante delicto is set. Looking correctly define the concept of presumption of flagrante delicto and check whether current regulations about is correct and suitable for their purposes. It is considered the use of the coprocessed statement as proof of charge for conviction in flagrant criminal cases. Finally, we study the situations where there is a legitimated advance in the privacy of people, provokes the flagrant verification of an illicit act alien to the one that gave progress to the interference.

Keywords: Criminal red-handed. Fundamental Rights. Presumption in fraganti crime. Criminal Procedure. 


\section{REFERENCES}

CABANELLAS, Guillermo. Diccionario enciclopédico de derecho usual, Heliasta, Buenos Aires, 1981, Tomo IV.

CLARIÁ OLMEDO, Jorge A. Derecho Procesal Penal, actualizado por Jorge

E. Vázquez Rossi, Rubinzal Culzoni, Santa Fe, 1998, Tomo I.

FERRAJOLI, Luigi. Principia iuris. Teoría del derecho y de la democracia, trads. Alfonso Ruiz Miguel y Perfecto Andrés Ibañez, Trotta, Madrid, 2011, Volumen II.

GAVARA DE CARA, Juan Carlos. Derechos fundamentales y desarrollo legislativo. La garantía del contenido esencial de los derechos fundamentales en la Ley Fundamental de Bonn, Centro de Estudios Constitucionales, Madrid, 1994.

HASSEMER, Winfried. El principio de proporcionalidad como límite de las intervenciones jurídico-penales, en AA.VV., Límites al derecho penal, Atelier, Barcelona, 2014.

JAÉN VALLEJO, Manuel. Tendencias actuales de la jurisprudencia constitucional penal: Las garantías del proceso penal, Dykinson, Madrid, 2002. KANOVITZ, Jacqueline R. Constitucional Law, thirteenth edition, Rutledge, New York, 2012.

KREHL, Christoph. Karlsruher Kommentar zur Strafprozessordnung, Frankfurt a. M., Beck, 2013.

MANZINI, Vincenzo. Tratado de derecho procesal penal, trad. de Santiago Sentís Melendo y Marino Ayerra Redín, Ejea, Buenos Aires, 1953, Tomo IV.

MUÑOZ CONDE, Francisco, La búsqueda de la verdad en el proceso penal, $3^{a}$ edición, Hammurabi, Buenos Aires, 2007.

RODRIGO, Fernando M. Hacia una aplicación más imparcial de la prisión preventiva, en, AA.VV., Revista Jurídica de Derecho Procesal, del Instituto Panamericano de Derecho Procesal - Capítulo Paraguay, primera edición, Director Joel Melgarejo Allegretto, Editorial Marben Editora \& Gráfica S.A., 2013. RUBIANES, Carlos J. Manual de derecho procesal penal, Depalma, Buenos Aires, 1978, Tomo III.

SANGUINÉ, Odone. Prisao cautelar, medidas alternativas e direitos 
fundamentais, Gen Editora Forense, Río de Janeiro, 2014.

SOLER, Sebastián. Derecho Penal Argentino, $4^{\circ}$ edición, $10^{\circ}$ reimpresión, TEA, Buenos Aires, 1992, Tomo II.

TARUFFO, Michele. La prueba de los hechos, trad. Jordi Ferrer Beltrán, Trotta, Madrid, 2002.

TARUFFO, Michele. Simplemente la verdad, trad. Daniela Accatino Scagliotti, Marcial Pons, Madrid, 2010.

YACOBUCCI, Guillermo J. La flagrancia, Hammurabi, Buenos Aires, 2017. 